MELO, R.T. et al. Lactobacillus helveticus e sua importância na indústria de laticínios. PUBVET, Londrina, V. 5, N. 9, Ed. 156, Art. 1057, 2011.

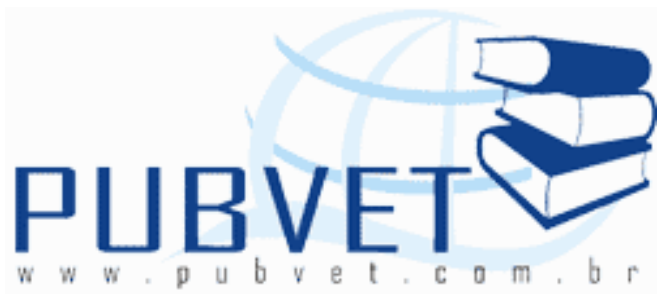

PUBVET, Publicações em Medicina Veterinária e Zootecnia.

\title{
Lactobacillus helveticus e sua importância na indústria de laticínios
}

Roberta Torres de Melo ${ }^{1,2}$, Guilherme Paz Monteiro², Letícia Ríspoli Coelho ${ }^{1,2}$, Priscila Christen Nalevaiko², Eduardo Almeida Freitas ${ }^{2}$, Eliane Pereira Mendonça ${ }^{1,2}$, Daise Aparecida Rossi ${ }^{1,2}$

${ }^{1}$ Programa de Pós-Graduação em Medicina Veterinária da Universidade Federal de Uberlândia;

${ }^{2}$ Laboratório de Biotecnologia Animal e Aplicada da Universidade Federal de Uberlândia.

\section{Resumo}

Lactobacillus helveticus podem ser obtidos de leite fermentado, soro fermento, fermentos láticos e queijos como Emmental, Gruyère, Parmesão e Provolone. Cepas de L. helveticus podem ser utilizadas em bioreatores para produção de ácido lático em vários substratos que representam agressão ao meio ambiente. $\mathrm{A}$ atividade proteolítica desse agente é geralmente reconhecida como forte entre as bactérias do ácido lático. Devido às suas características e seu potencial de aplicação em vários alimentos industriais, e em particular, na maturação de queijos, o elevado interesse nesse tópico incentiva cada vez mais o avanço tecnológico da indústria de laticínios. 
MELO, R.T. et al. Lactobacillus helveticus e sua importância na indústria de laticínios. PUBVET, Londrina, V. 5, N. 9, Ed. 156, Art. 1057, 2011.

\title{
Lactobacillus helveticus and its importance in the dairy industry
}

\begin{abstract}
Lactobacillus helveticus may be obtained from fermented milk, whey starter, yeast lactic and cheeses like Emmental, Gruyere, Parmesan and Provolone. Strains of $L$. helveticus may be used in bioreactors for production of lactic acid on various substrates that represent harm to the environment. The proteolytic activity of this agent is generally recognized as strong among the lactic acid bacteria. Due to its characteristics and its potential application in various food industry, and particularly in cheese ripening, the high interest in this topic is increasingly encouraging the technological advancement of the dairy industry.
\end{abstract}

\section{Introdução}

De acordo com o Bergey's Manual of Determinate Bacteriology, o gênero Lactobacillus é composto por bacilos Gram positivos, regulares e não esporulados. Possuem morfologia celular variando de bacilos longos e finos, até, algumas vezes, como bacilos curvados e pequenos (Kandler e Weiss, 1986). Também é freqüente a forma de cocobacilos, sendo comum a formação de cadeias. A motilidade não é usual e, quando presente, dá-se por meio de flagelos peritriquicos. Algumas cepas exibem corpo bipolar, granulações internas ou aparência de baga, com reação à coloração de Gram ou azul de metileno. Os grandes corpos bipolares, provavelmente, contém polifosfato e aparecem muito densos quando observados através de microscópio eletrônico. O tamanho dos bacilos e o grau de curvatura é dependente da idade da cultura. Formas irregulares são observadas dentro de crescimento simbiótico ou sobre alta concentrações de glicina, D-aminoácidos ou antibióticos com ação na parede celular. A porcentagem de $\mathrm{G}+\mathrm{C}$ do DNA é 32-53. 
MELO, R.T. et al. Lactobacillus helveticus e sua importância na indústria de laticínios. PUBVET, Londrina, V. 5, N. 9, Ed. 156, Art. 1057, 2011.

O metabolismo fermentativo dos lactobacilos produz como metade do produto final do carbono, o lactato, que usualmente não é fermentado. Produtos adicionais são acetato, etanol, $\mathrm{CO}_{2}$, formato ou succinato. Não são produzidos ácidos voláteis com mais de dois átomos de carbono (Sneath et al., 1994).

Os Lactobacillus são microaerófilos e quando em crescimento na superfície em meios sólidos, geralmente o desenvolvimento é melhor em anaerobiose ou pressão de oxigênio reduzido e $5-10 \%$ de $\mathrm{CO}_{2}$; alguns são anaeróbios em isolamento. Nos meios usuais de crescimento, os lactobacilos raramente produzem pigmentos, que quando presentes, são amarelados, laranja-ferrugem ou vermelho-tijolo. Crescem em temperaturas que variam de 2 a $53^{\circ} \mathrm{C}$, com ótimo, geralmente, a $30-40^{\circ} \mathrm{C}$. São acidúricos, com pH ótimo entre 5.5 e $6.2 ; 0$ crescimento ocorre a 5.0 ou menos. A taxa de crescimento é freqüentemente reduzida em meios neutros ou alcalinos. Nas diversas espécies, a redução do nitrato não é usual, podendo acontecer porém, quando o pH terminal é estabilizado acima de 6.0 (Kandler e Weiss, 1986)

Normalmente lactobacilos não possuem capacidade de liquefazer a gelatina ou digerir a caseína, mas, pequena quantidade de nitrogênio solúvel é produzida por muitas espécies. Indol e $\mathrm{H}_{2} \mathrm{~S}$ não são produzidos e a catalase e citocromo são negativos, devido ausência de porfirina. Todavia, algumas cepas decompõem peroxidase por uma pseudo-catalase e a reação da benzidina é negativa. São encontrados em derivados do leite, grãos, produtos de carne e peixe, água, esgoto, cerveja, vinho, frutas e suco de frutas, conservas de vegetais, silagem, chucrute e massas fermentadas. Fazem parte da flora normal da boca, trato intestinal e vagina de alguns animais homotérmicos, incluindo o homem, sendo a patogenicidade rara (Sneath et al., 1986).

Os lactobacilos são organismos extremamente fastidiosos e adaptados a complexos substratos orgânicos. Eles não só requerem carboidratos como energia e fonte de carbono, mas também nucleotídeos, aminoácidos e vitaminas. O 
MELO, R.T. et al. Lactobacillus helveticus e sua importância na indústria de laticínios. PUBVET, Londrina, V. 5, N. 9, Ed. 156, Art. 1057, 2011.

requerimento por ácido fólico, riboflavina, fosfato de piridoxina e ácido paminobenzóico são difundidos entre várias espécies, sendo a riboflavina o composto mais frequentemente requerido. Biotina e vitamina $B_{12}$ são essenciais para somente algumas espécies. Cepas vitaminas dependentes são comumente usadas em bioensaios de vitaminas e são listadas em catálogos de muitas coleções de culturas. O padrão de aminoácidos também diferem entre espécies e até entre cepas. (Kandler e Weiss, 1986).

$\mathrm{Na}$ formulação de meios de cultura para o gênero, deve-se observar que a carne é nutriente essencial quando o meio contém carboidratos fermentáveis, peptona, extrato de levedura e extrato de carne. A suplementação dos meios com suco de tomate, manganês, acetato e ésteres de ácido oleico, especialmente Tween 80, são estimulantes ou até essenciais para muitas espécies. Estes compostos estão incluídos no meio extensamente utilizado para crescimento e isolamento formulado por Man et al. (1960), o meio MRS.

A dificuldade na classificação é discutida por diversos autores, já que o gênero Lactobacillus comporta mais de 50 espécies, sendo algumas, muito distantes geneticamente umas das outras e outras altamente relacionadas, variando somente na extensão da fermentação de alguns carboidratos (Lortal et al., 1997; Torriani et al., 1994; Kandler e Weiss, 1986). Rearranjamento da taxonia do gênero são esperados (Tailliez et al., 1996; Torriani et al., 1994; Stackebrandt e Teuber, 1988; Gasser, 1970).

\section{Lactobacillus helveticus}

Os $L$. helveticus apresentam bom crescimento a $40-45^{\circ} \mathrm{C}$ com máximo a $50-$ $52^{\circ} \mathrm{C}$, mas não se desenvolvem em temperaturas inferiores a $15^{\circ} \mathrm{C}$. Geralmente resistem a temperaturas de $60^{\circ} \mathrm{C}$ por 90 minutos (Furtado, 1990). Os fatores essenciais para crescimento são cálcio, pirodoxal ou piridoxamina, sendo que, ácido fólico, vitamina $B_{12}$ e tiamina não são requeridos (Kandler e Weiss, 1986). 
MELO, R.T. et al. Lactobacillus helveticus e sua importância na indústria de laticínios. PUBVET, Londrina, V. 5, N. 9, Ed. 156, Art. 1057, 2011.

L. helveticus utilizam para fermentar a lactose, a via glicolítica ou EmbdenMeyerhof-Parnas, sendo a redução do ácido pirúvico a ácido lático catalisada pela enzima lactato desidrogenase (Arnaud e Guiraud, 1985). São homofermentativos e fortes produtores de ácido lático, fermentando a lactose até concentrações de aproximadamente 2,7\% (Furtado, 1990). Torriani et al. (1994) consideram que esses microrganismos produzem ácido lático em concentrações maiores que $2 \%$. De fato, Fortina et al. (1998) verificaram que há diferenças na capacidade de acidificação em cepas de $L$. helveticus, e recomendam, que essa característica deve ser utilizada para seleção de culturas para perfis biotecnológicos de interesse.

Na caracterização fenotípica, o L. helveticus é geralmente imóvel e quanto ao perfil de fermentação de carboidratos, pertence ao grupo 1, das espécies obrigatoriamente homofermentativas. Não fermentam amigdalina, arabinose, celobiose, esculina, gluconato, manitol, melezitose, melibiose, rafinose, ribose, salicina, sorbitol, sacarose e xilose ( $90 \%$ ou mais das cepas negativas), fermentam a galactose, glicose e lactose ( $90 \%$ ou mais cepas positivas), 11 a $89 \%$ das cepas positivas para frutose, maltose, manose e trealose e fermentação variável do N-acetil-glicosamina (Torriani et al., 1994).

Na homologia DNA/DNA, L. helveticus formam um estreito grupo homólogo genomicamente, junto com cepas antigamente denominadas "L. jugurti", mas não próxima a cepas $L$. delbrueckii subsp. bulgaricus, L. delbrueckii subsp. lactis e $L$. gasseri. A filogenia relacionada entre $L$. helveticus e $L$. acidophilus é indicada pela porcentagem de homologia de DNA de 20-30\% entre as duas espécies. Para confirmar essa proximidade, sondas de DNA espécie-específicas para detecção de L. helveticus foram construídas, e os autores, observaram fraca hibridação com o DNA de algumas estirpes de $L$. acidophilus, confirmando a fechada relação filogenética entre essas duas espécies de lactobacilos (Pilloud e Mallet, 1990). 
MELO, R.T. et al. Lactobacillus helveticus e sua importância na indústria de laticínios. PUBVET, Londrina, V. 5, N. 9, Ed. 156, Art. 1057, 2011.

\section{Isolamento e caracterização}

L. helveticus podem ser obtidos de leite fermentado, soro fermento, fermentos láticos e queijos como Emmental, Gruyère, Parmesão e Provolone. Estudos recentes demonstram, que apesar de $L$. helveticus apresentarem baixa resistência a bile in vitro, podem sobreviver a passagem pelo trato gastrointestinal de humanos. Essa constatação pode representar inúmeras novas aplicações potenciais para essa espécie (Shinoda et al., 2001). Várias outras características têm sido estudadas em L. helveticus, inclusive, a capacidade de algumas cepas produzirem na fermentação do leite ou soro, peptídios com capacidade hipotensora semelhante à enzima conversora de angiotensina, característica confirmada em testes realizados em ratos (Yamamoto et al., 1999).

O isolamento dos lactobacilos termófilos não apresenta dificuldade, podendo ser utilizado para esse fim, o meio MRS com pH ajustado em 5.4, incubado em anaerobiose a $43^{\circ} \mathrm{C}$ por $24-48$ horas. Esse meio atende às exigências nutricionais da maioria dos lactobacilos e não contém nenhum agente inibidor, e quando utilizados na temperatura e $\mathrm{pH}$ indicados, realmente selecionam somente os lactobacilos termófilos acidúricos (Kandler e Weiss, 1986; Lortal et al., 1992)

A diferenciação do L. helveticus de outros lactobacilos termofílicos, porém, tem sido considerada uma etapa complicada. Para diferenciação é comum a observação dos fenótipos apresentados em provas de fermentação de açúcares, que associadas à temperatura mínima de crescimento, podem ser utilizadas em chaves de identificação, como as organizadas por Hammes et al., (1992).

O Bergey's Manual of Systematic Bacteriology coloca o L. helveticus no grupo de espécies obrigatoriamente homofermentativas, fermentando hexoses quase completamente a ácido lático, seguindo a via glicolítica e não utilizando as pentoses (Kandler e Weiss, 1986). A habilidade do L. helveticus (galactose positiva) de utilizar a galactose, pode ser usada para sua diferenciação de $L$. delbrueckii subsp. bulgaricus e subsp. lactis (galactose negativa). Porém, deve-se 
MELO, R.T. et al. Lactobacillus helveticus e sua importância na indústria de laticínios. PUBVET, Londrina, V. 5, N. 9, Ed. 156, Art. 1057, 2011.

levar em consideração que cerca de $10 \%$ ou mais das cepas de L. helveticus podem ser inábeis em fermentar completamente a galactose (Torriani et al., 1994). Além da diferenciação, esse fato é considerado muito importante, já que a acumulação e subsequente metabolismo da galactose por bactérias não láticas indesejáveis, podem conduzir a uma maturação atípica ou defeitos em queijos como o escurecimento da mussarela (Jonhson e Olson, 1985; Mukherjee et al., 1994; Matzdorf et al., 1994; Furtado, 1997).

Somente a utilização de perfis de fermentação para identificação de $L$. helveticus, podem conduzir a erros e devem ser associados a outras técnicas. Mudanças em termos de fermentação da frutose, maltose e trealose foram encontradas após estudos contínuos em cepas de L. helveticus isolados de fermentos naturais (Fortina et al., 1998). Os autores observaram que as alterações no perfil de fermentação foram associadas à alterações na atividade proteolítica e de resistência a antibióticos e à lisozima. Também Reinheimer et al. (1995) estudando L. helveticus ATCC 15807 observaram que durante o crescimento dentro de condições ótimas, são espontaneamente produzidas variantes com habilidade para fermentar manose $(0,01 \%$ da população total) e frutose $(0,004 \%)$, que permanecem estáveis então por várias subculturas e que não reverteram durante todo o experimento. Hébert et al. (2000) estudaram cepas de $L$. helveticus da coleção CRL (provenientes de culturas de referência ATCC, NCDO, CNRZ e queijo Grana italiano) e observaram que todas as cepas foram capazes de fermentar a glicose, manose, lactose e $\mathrm{N}$-acetil glucosamina, todas inábeis na utilização da amigdalina, manitol, arabinose, celobiose, melizitose, melibiose, ramnose, ribose, sorbitol e xilose, porém, a fermentação da galactose, frutose e trealose foi cepa dependente. Essas variações no perfil fermentativo devem ser analisadas com cuidado, pois podem levar a erros na identificação. 
MELO, R.T. et al. Lactobacillus helveticus e sua importância na indústria de laticínios. PUBVET, Londrina, V. 5, N. 9, Ed. 156, Art. 1057, 2011.

Atualmente a diferenciação de lactobacilos termófilos podem ser realizadas através de perfil de enzimas de parede celular em gel de proteína SDS-PAGE modificado. Em estudos realizados por Lortal et al. (1992) na cepa de $L$. helveticus ATCC 12046, os autores encontraram 3 estruturas proteicas em camadas (layer), na parede celular. Para extração eficiente e seletiva da proteína, foi realizado tratamento com $\mathrm{LiCl} 5 \mathrm{M}$. O componente externo foi identificado como uma capa não glicosilada de uma proteína de 53 kDa (S-layer). Quando foi preparado um extrato de células intactas (através de congelamento), foi demonstrado que S-layer é uma proteína oblíqua em engradado ( $a=4,5 \mathrm{~nm}, \mathrm{~b}=$ 9,5nm, gama $=75 \varnothing)$, que cobre completamente a superfície da célula. Os autores observaram ainda, que a viabilidade das estirpes não diminuiu significativamente após a extração, e além disso, que a proteína S-layer, reapareceu quando se permitiu que as células tratadas crescessem novamente. Quando purificaram a proteína S-layer, foi determinado um alto conteúdo (44\%) de aminoácidos hidrofóbicos, com a seqüência N-terminal composta principalmente por alanina, treonina, asparagina e ácido aspartico. S-layer é uma enzima hidrolase, com diferentes funções, localizada na parte externa da bactéria e pode ser determinada por SDS-PAGE.

Outros métodos de identificação de Lactobacillus sp. foram utilizadas em organismos isolados de fermento lático e de leites fermentados e comparados a resultados obtidos por SDS-PAGE. Utilizando determinação de rRNA-23S por sondas de nucleotídeos alvo e por análise numérica de perfil eletroforético de proteínas, os genes rRNA-23S de vários lactobacilos foram parcialmente seqüenciados e provas complementares de oligonucleotídeos específicos foram sintetizados. Sondas espécie específicas de L. delbrueckii, L. helveticus e $L$. paracasei e sondas grupo específicas para $L$. casei, Lb. rhamnosus e $L b$. casei / $L$. paracasei / L.rhamnosus foram determinadas. Proteínas de conjunto de células extraídas de cepas cultivadas também foram examinadas usando SDS-PAGE. A 
MELO, R.T. et al. Lactobacillus helveticus e sua importância na indústria de laticínios. PUBVET, Londrina, V. 5, N. 9, Ed. 156, Art. 1057, 2011.

comparação numérica dos resultados com os padrões eletroforéticos de proteínas revelaram grupos definitivos, com boa correlação com diferentes espécies (Hertel et al., 1993).

Gatti et al. (1997) realizaram SDS-PAGE fingerprinting de proteínas de parede celular extraídas de 38 estirpes de L. helveticus, 27 de L. delbrueckii subp. bulgaricus, 18 de L. acidophilus, 7 de L. fermentum, 8 de Streptococcus thermophillus, 4 de Enterococcus faecium (Streptococcus faecium) e 9 de E. faecalis (S. faecalis), isolados de soro fermento natural e queijos. Os autores encontraram uma proteína de aproximadamente $50 \mathrm{kDa}$ (S-layer) que foi característica de todas as cepas de $L$. helveticus e 2 proteínas de parede celular de aproximadamente 20 e 30 kDa foram típicas da espécie de L. delbrueckii. A diferenciação entre as sub-espécies lactis e bulgaricus não foi possível com a utilização da técnica eletroforética usada, mas, as outras espécies termofílicas estudadas, apresentaram padrões de proteína de parede celular que permitiram a diferenciação de L. helveticus e L. delbrueckii. Os autores consideraram a determinação da estrutura S-layer, como um método fidedigno de identificar $L$. helveticus.

Lortal et al. (1997) utilizaram o padrão de hidrolases de peptoglicanos de parede celular para obter características de interesse na identificação de lactobacilos após observarem que essas enzimas eram estruturas altamente conservadas. A técnica utilizada avaliava o peso molecular e a forma típica de bandas líticas formadas graças a introdução de um microrganismo no gel ( $M$. luteus) e permitiu separar com pequenas variações de intensidade 10 espécies diferentes de 94 estirpes de lactobacilos. Além disso, espécies íntimas filogeneticamente como L. sake e L. curvatus ou L. acidophilus e L. helveticus foram identificadas com sucesso.

Em 1998, Callegari et al., estudaram a estrutura de superfície (S-layer) de L. helveticus CNRZ 892 e determinaram que era composta de monômeros de 
MELO, R.T. et al. Lactobacillus helveticus e sua importância na indústria de laticínios. PUBVET, Londrina, V. 5, N. 9, Ed. 156, Art. 1057, 2011.

proteínas de $43 \mathrm{kDa}$ organizado em fileiras ordenadas. Para este estudo, o gene que codifica esta proteína $(\mathrm{slpH})$ foi clonado em $E$. coli e sequenciado. SIpH consiste de 440 códons e é precedido por um sítio que liga o ribossoma (RBS) e seguido por um suposto terminador rho-independente. Análises de Northern-Bloth (técnica molecular que utiliza hibridização), revelaram que esta slpH é um gene monocistrônico e a seqüência de aminoácido deduzida de SIpH mostra um peptídio líder de 30 aminoácidos. O gene slpH foi amplificado por uma reação de polimerase em cadeia e o fragmento, transportando o gene completo de RBS para o códon de parada, foi clonado em um gene de expressão do vetor Lactococcus. Lactococcus lactis MG1363 transportando o plasmídio resultante, secretou um monômero S-layer com a mesma massa molecular autêntica do $L$ helveticus CNRZ $892 \mathrm{SIpH}$, como comprovado por SDS-PAGE. Esse trabalho caracterizou a proteína S-layer como espécie-específica, podendo ser utilizada como ferramenta taxonômica. Microscópio imunoeletrônico revelou que $\mathrm{SIpH}$ foi ligado a parede celular do célula do Lactococcus em pequenos aglomerados e acumulado no meio de crescimento como pequenas folhas.

Hébert et al. (2000) utilizaram o perfil de proteínas em SDS-PAGE, padrão de fermentação e sequência do rRNA 16 S para identificar cepas de $L$. helveticus e Lactobacillus delbrueckii subsp. lactis. Os autores concluíram que o perfil de proteínas SDS-PAGE confirmou com sucesso a caracterização taxonômica dessas cepas, sendo equivalente ao método rRNA 16S. O perfil de fermentação foi hábil na caracterização da maioria das cepas, porém, a não fermentação da sacarose por uma cepa de Lactobacillus delbrueckii subsp. lactis, o caracterizou erroneamente como L. helveticus. A classificação equivocada pelo perfil de fermentação foi confirmada pelo SDS-PAGE e sequência do rRNA 16S. 
MELO, R.T. et al. Lactobacillus helveticus e sua importância na indústria de laticínios. PUBVET, Londrina, V. 5, N. 9, Ed. 156, Art. 1057, 2011.

\section{Diversidade}

Informações sobre parentesco ou similaridade genética possuem aplicações importantes em diferentes áreas da ciência, permitindo identificar linhagens ou populações que devem ser mantidas para preservar a máxima diversidade genética (Thormann e Osborn, 1992). Os procedimentos clássicos de caracterização de linhagens bacterianas, tal como características bioquímicas ou nutricionais, análise de proteínas totais ou a composição da proteínas de membrana, reações imunológicas e do conteúdo plasmático não permitem, em geral, distinguir linhagens aparentemente da mesma espécie (Le Borgeois et al., 1993).

Os métodos que permitem medir a diversidade entre linhagens aparentadas podem ser baseados na comparação da sequência dos seus genomas ou da sequência do rRNA ribossomal $16 \mathrm{~S}$ e a medida da homologia DNA/DNA. Dois métodos são suficientemente rápidos para poder analisar as numerosas linhagens e podem revelar as diferenças entre linhagens de uma mesma espécie, a eletroforese de grandes fragmentos de DNA em campos pulsados e o randomly amplified polymorphic DNA-RAPD (Welsh e Mcclelland, 1990; Willians et al., 1990; Tailliez et al., 1996).

O RAPD é uma técnica que foi desenvolvida independentemente por Welsh e Mcclelland (1990) e Williams et al. (1990). O método é baseado na amplificação ao acaso do DNA alvo, usando como iniciador (primer) um oligonucleotídeo com cerca de 10 bases de sequência arbitrária, sob condições de baixa estringência. $O$ primer encontra várias sequências complementares ao longo do genoma e quando essas sequências estão a poucas centenas de pares de bases de distância umas das outras e em fitas opostas, a região inclusa pode ser amplificado pela polimerase. A ausência deste produto amplificado em outro indivíduo, pode ser pela perda do sítio no DNA devido a mutação, deleção ou inserção (Muralidharan e Wakeland, 1993). De acordo com os produtos amplificados, polimorfismos são 
MELO, R.T. et al. Lactobacillus helveticus e sua importância na indústria de laticínios. PUBVET, Londrina, V. 5, N. 9, Ed. 156, Art. 1057, 2011.

revelados. Estes marcadores são fáceis de serem detectados, pois não requerem informações sobre a sequência de DNA a ser amplificado ou a síntese de primers específicos. Duas outras vantagens são a automatização do processo e a pequena quantidade de DNA requerida (Thormann e Osborn, 1992).

Apesar das vantagens enumeradas, a técnica RAPD possui algumas limitações. Mudanças mínimas nas condições da reação podem afetar significativamente os produtos da amplificação, sendo a reprodutibilidade dos padrões a maior preocupação de muitos pesquisadores. A marca da polimerase, do termociclador, a temperatura de anelamento e o primer, são fatores importantes na obtenção de bons rendimentos e padrões de fragmentos de DNA (Wolf et al., 1993).

Na utilização do RAPD para caracterizar 78 culturas de lactobacilos com 2 primers diferentes, Tailliez et al. (1996) concluíram que este era um bom método para identificação de tipagem de microrganismos e possui importantes aplicações potenciais não só para a constituição e enriquecimento dirigido a coleções, mas igualmente, para a microbiologia fundamental, que se combinada a outras técnicas, facilitariam a identificação de novas espécies bacterianas.

Cocconcelli et al. (1997) utilizaram para estudo da microflora de soro fermento proveniente da fabricação de queijos Parmigiano Reggiano, técnicas moleculares de RAPD e rRNA-16S. Análises de RAPD facilitaram a identificação das cepas de Lactobacillus envolvidos em associação microbiológica, permitindo também o estudo da dinâmica da população durante 2 ciclos da fermentação em soro fermento que foram coletadas a $0,6,12,18$ e 24 horas de fermentação. Análises de RAPD fingerprint revelaram a presença de 4 biotipos que dominaram o processo de fermentação do soro. Análise da sequência de rRNA-16S demonstraram que estas cepas isoladas de soro correspondiam a $L$. helveticus e L. delbrueckii subsp. lactis. 
MELO, R.T. et al. Lactobacillus helveticus e sua importância na indústria de laticínios. PUBVET, Londrina, V. 5, N. 9, Ed. 156, Art. 1057, 2011.

Giraffa et al. (1998), caracterizaram 23 cepas de L. helveticus isoladas de soro fermento e queijos italianos através da ribotipagem, perfil de plasmídios e RAPD. Diferenças entre as cepas foram detectadas pelas 3 técnicas utilizadas, porém, os autores constataram que em alguns casos, o RAPD foi capaz de demonstrar diferenças não detectadas pelas outras duas técnicas e que a heterogeneidade encontrada entre as cepas, era dependente do seu local de origem.

Diferenças substanciais em várias características tecnológicas importantes foram observadas entre $L$. helveticus isolados de fermentos naturais (Giraffa et al., 2000). Os autores utilizaram análise estatística multivariada para analisar os dados obtidos na ribotipagem (rRNA 16S) e RFLP (restriction fragment lengh polymorphism). Os resultados permitiram a compreensão com bases mais sólidas, da associação de características genéticas e tecnológicas observadas nas cepas, com o tipo de queijo em que foram isoladas, demonstrando o significado funcional e ecológico de biotipos de $L$. helveticus em culturas naturais associadas ao seu local de origem.

\section{Comportamento na fermentação}

Cepas de L. helveticus podem ser utilizadas em bioreatores para produção de ácido lático em vários substratos que representam agressão ao meio ambiente, em particular o soro de queijo. O estudo da cinética da produção ácido e da atividade proteolítica e lipolítica do microrganismo podem fornecer importantes informações sobre seu comportamento nos reatores, na produção de fermentos láticos e nos processos de maturação de queijos.

Utilizando gradientes de pH 4.3 a 6.3 e células imobilizadas de $L$. helveticus, em fermentação contínua tendo como substrato soro, Norton et al. (1993) observaram em microscópio de fase, diminuição da cadeia de lactobacilos. Quando, porém, utilizaram extrato livre de células do mesmo microrganismo, 
MELO, R.T. et al. Lactobacillus helveticus e sua importância na indústria de laticínios. PUBVET, Londrina, V. 5, N. 9, Ed. 156, Art. 1057, 2011.

houve alongamento progressivo da cadeia em $\mathrm{pH}$ de 5.1 a 6.3, sendo que na fermentação contínua, as células foram menos dependentes do $\mathrm{pH}$. Os autores credenciaram este fenômeno ao tempo longo de resposta das células às mudanças constantes do $\mathrm{pH}$ do substrato.

Norton et al. (1994b) utilizaram L. helveticus imobilizados em suporte de carragena para fermentar substrato com permeado de soro suplementado com $33 \%$ de caldo de feijão em diferentes níveis de $\mathrm{pH}$. No estudo cinético da fermentação contínua, foi observado uma taxa máxima de ácido lático de $28.5 \mathrm{~g}$ por litro/hora em pH 5.5. Os autores determinaram que as células que permaneceram ligadas ao suporte de carragena foram responsáveis por $75-85 \%$ da produção de ácido e biomassa, em pH variando de 4.7 a 6.3, e de aproximadamente $90 \%$, quando o $\mathrm{pH}$ foi controlado e fixado em 4.3.

Vários fatores podem interferir na quantidade de ácido produzida pelos $L$. helveticus, como a formulação do meio para pré cultura ou cultura e o substrato utilizado. Na produção de ácido lático, quando foi utilizado soro clarificado e ultrafiltrado como substrato, a produção foi de $4.4 \mathrm{~g} /$ /itro/hora, enquanto que, o uso de hidrolisados de soro produziu até $5.5 \mathrm{~g} /$ litro/hora (Amrane e Prigen, 1993).

Também a alimentação do gado, que modificam a composição do leite possuem, consequentemente, influência na produção de ácido. Num experimento conduzido por Ibrahim (1991), o autor alimentou 3 grupos de búfalas com diferentes níveis de extrato de levedura e utilizou o leite para cultivar diferentes cepas de L. helveticus por diferentes períodos de incubação. Os resultados das análises de variância indicaram que o comportamento das culturas investigadas (número de microrganismos, acidez) foram significativamente afetados pelo período de incubação, leite obtido dos diferentes grupos de animais e sua interação, indicando que as diferenças no comportamento não são independentes. O tipo de leite também influenciou na produção de ácido por $L$. 
MELO, R.T. et al. Lactobacillus helveticus e sua importância na indústria de laticínios. PUBVET, Londrina, V. 5, N. 9, Ed. 156, Art. 1057, 2011.

helveticus em um experimento utilizando leite de cabra e vaca e diferentes períodos de incubação (Ibrahim et al., 1990). Os autores observaram maior produção de ácido em leite de cabra em todas as repetições.

Estudando cepas variantes de L. helveticus CRL 1062 que coagulavam o leite lentamente, Hébert et al. (2000) verificaram que as cepas possuíam todos os componentes essenciais conhecidos necessários para utilizar caseína como fonte de carbono, incluindo atividades funcionais de proteinase e peptidase. Os requerimentos nutricionais nesses variantes foram similares a de cepas parentais, porém, os autores encontraram um defeito na habilidade de síntese da guanina monofosfato (GMP). Essa observação foi apoiada pelo fato de que a adição de guanina e xantina ao leite, substratos pobres em compostos purínicos, restaurou o fenótipo original da cepa de $L$. helveticus, capaz de coagular rapidamente o leite.

A temperatura e o $\mathrm{pH}$ também influenciaram a produção de lactato por cepas de L. helveticus modificadas geneticamente, alterando a expressão da enzima lactato desidrogenase. As estirpes geneticamente modificadas apresentaram atividade de acidificação 53 a 93\% maior que as cepas selvagens a $41^{\circ} \mathrm{C}$ e pH 5.9 (Kyla-Nikkila et al., 2000).

\section{Atividade proteolítica e autólise}

A atividade proteolítica do L. helveticus são geralmente reconhecidas como forte entre as bactérias do ácido lático. Devido suas características e sua potencial aplicação em várias alimentos industriais, e em particular, na maturação de queijos, o interesse nesse tópico tem sido aumentado nos últimos anos.

Os requerimentos nutricionais de $L$. helveticus são extensos e dependem da suplementação por aminoácidos exógenos. Sistemas proteolíticos representam papel determinante no crescimento ótimo das espécies no leite, onde as caseínas 
MELO, R.T. et al. Lactobacillus helveticus e sua importância na indústria de laticínios. PUBVET, Londrina, V. 5, N. 9, Ed. 156, Art. 1057, 2011.

são hidrolisadas por proteinases associadas a parede celular e peptídeos são liberados devido diversas atividades de peptidase (Torriani et al., 1994).

Num estudo da atividade de peptidase de lactobacilos, L. helveticus YB1 resultou a mais proteolítica entre as espécies consideradas; ele hidrolizava tanto $\alpha$-caseína quanto $\beta$-caseína, e era dotado de altos níveis de aminopeptidases gerais (AP) e prolina iminopeptidase. Atividade de carboxipeptidase foram ausentes nas cepas testadas (Hickey et al., 1986).

Experimentos estudando a hidrólise da caseína $\mathrm{C}_{14}$ por proteinases aderidas a parede celular de muitas cepas de $L$. helveticus, confirmaram a degradação de $\alpha$ e $\beta$-caseínas (Ezzat et al., 1985). A maioria das cepas de L. helveticus são capazes de quebrar tanto $\alpha$-caseína quanto a $\beta$-caseína, possuindo alta atividade de aminopeptidase em substratos de lisina e leucina (Ginzinger e Sebastiani, 1993).

Além do uso na maturação de queijos, outras aplicações tem sido encontradas para produtos do metabolismo proteico de L. helveticus. Peptídios derivados de $\alpha_{\mathrm{S} 1}$ e $\beta$-caseína, isolados da atividade proteolítica de $L$. helveticus CP790 foram testados para diminuição da pressão arterial. O efeito obtido foi comparado a enzima conversora da angiotensina (capaz de diminuir a pressão sanguínea). O efeito anti hipertensivo dos peptídeos foi efetiva em ratos por administração oral $(5 \mathrm{mg} / \mathrm{kg})$, quantidade contida em $5 \mathrm{ml}$ de leite inoculado contendo $0,3 \%$ de peptídios (Yamamoto et al., 1994). Os autores também utilizaram variantes defeituosos para atividade de proteinase para cultivar leite e este não mostrou efeito anti hipertensivo nos ratos, comprovando sua ação in vivo.

Em estudo da localização citológica das enzimas proteolíticas de $L$. helveticus, Vescovo e Bottazzi (1979) demonstraram que estas peptidases e aminopeptidases estavam localizadas na maior parte no citoplasma e atividade de iminopeptidase na parede celular. 
MELO, R.T. et al. Lactobacillus helveticus e sua importância na indústria de laticínios. PUBVET, Londrina, V. 5, N. 9, Ed. 156, Art. 1057, 2011.

Fermentos autolíticos de muitos microrganismos podem ser usados em substituição a culturas tradicionais ou como aceleradores da maturação de queijos. Na lise, o conteúdo intracelular, e consequentemente, as enzimas, ficam livres no meio e podem realizar mais rapidamente suas atividades sem necessitar do crescimento dos microrganismos (Fox e Law, 1991).

Alguns autores utilizaram o fermento previamente autolisado em algumas variedades de queijos, justificando que, quando se utiliza células ativas, além de enzimas, os microrganismos podem fermentar a lactose e produzir ácido lático e outros metabólitos de forma não controlada ou não desejável, fato que não acontece quando somente o extrato de células não viáveis e os complexos enzimáticos são adicionados. Enquanto estirpes autolíticas não são isoladas, caracterizadas e utilizadas na produção de fermentos comerciais, alguns pesquisadores tem estudado sua atuação, através de lise por choque térmico, na maturação de queijos.

Visando acelerar a maturação de queijos "Ras", foram realizados testes com adição de 0 (controle), 1 e $2 \%$ de fermento autolisado preparado com a incubação de $L$. helveticus em leite desnatado por 10 dias a $38^{\circ} \mathrm{C}$. As análises dos queijos não mostraram diferenças nos conteúdos de umidade e componentes químicos, porém, o aumento nos ácidos voláteis C:6-C:12, nitrogênio solúvel, tirosina e triptofano foram maiores e proporcionais à quantidade de fermento autolisado utilizado, durante toda a maturação. Estudos eletroforéticos indicaram que a proteólise foi mais pronunciada nos queijos tratados que nos controle e que a taxa de hidrólise foi proporcional a quantidade de fermento autolisado adicionado (Gomaa et al., 1992).

Ainda em queijos "Ras", Ammar et al. (1994) testaram a influência na umidade, acidez, frações de nitrogênio solúvel e ácidos graxos voláteis pelo uso de fermento de Lactococcus lactis subsp. lactis (controle) e 1 e $2 \%$ de fermento de $L$. helveticus autolisado. Os autores não encontraram diferenças significativas 
MELO, R.T. et al. Lactobacillus helveticus e sua importância na indústria de laticínios. PUBVET, Londrina, V. 5, N. 9, Ed. 156, Art. 1057, 2011.

nos conteúdos de umidade, sal no extrato seco, gordura e nitrogênio total, porém, o uso do fermento autolisado aumentou os níveis de ácidos graxos voláteis e nitrogênio solúvel após maturação por 2 meses. Na análise sensorial realizada após 3 meses de maturação, os escores alcançados pelos queijos tratados com 1 e $2 \%$ de fermento autolisado foi de 94 e 95 pontos, enquanto que, os queijos controle receberam nota 84. Valence et al. (2000) também verificaram uma maior atividade proteolítica com a utilização de L. helveticus autolíticos na fabricação de queijos suiços. Os resultados obtidos com o uso das cepas autolíticas, quando comparados aos queijos controle, mostrou que esses microrganismos podem ser utilizados para abreviar a maturação de queijos.

Estudando a autólise espontânea de cepas de bactérias propiônicas em meio de cultura, Carvalho (1994) observou que a autólise dessas cepas, acontecia após a observação do crescimento máximo (através da leitura espectrofotométrica a $650 \mathrm{~nm}$ ) seguida de uma fase de declínio relacionada a perda de viabilidade. A autólise foi confirmada através de microscopia eletrônica, onde o autor observou diferenças morfológicas nas culturas na fase exponencial de crescimento e fase de declínio. No decorrer da fase de autólise expontânea, vários estados de degradação foram observados. O autor relacionou hipóteses à autólise espontânea em meio de cultura, entre elas, a carência nutritiva associada à acidificação e temperatura adaptada à atividade do sistema autolítico.

Estudos conduzidos em E. coli e Salmonella typhimurium demonstraram que a vida celular depende sobretudo do $\mathrm{pH}$ intracelular (poder tamponante e força iônica do citoplasma) e da pressão de turgescência, diretamente ligada ao pH extracelular e à composição do meio (Ingraham, 1987). Kemper e Doyle (1993) sugeriram que a autólise celular é provocada por perturbações iônicas e de $\mathrm{pH}$ dentro da parede, incentivando a atividade do sistema autolítico em uma célula e tornando-a incapaz de regular estas mudanças com o meio exterior, sendo este enfraquecimento diretamente ligado a privação de nutrientes. 
MELO, R.T. et al. Lactobacillus helveticus e sua importância na indústria de laticínios. PUBVET, Londrina, V. 5, N. 9, Ed. 156, Art. 1057, 2011.

\section{Soro fermento natural}

Culturas endógenas de fermento lático podem ser definidas como aquelas que se formam sob o controle de fatores tecnológicos em um determinado ambiente, sem sofrer a influência de microrganismos de outra procedência trazidos pelo homem. A mais antiga cultura natural em soro é a empregada na produção do queijo Grana, sendo hoje, o soro fermento considerado uma cultura estabilizada sobre a microbiota termófila (Botazzi, 1977).

No Brasil, segundo Guimarães (1991) o soro fermento é preparado aquecendo a $70^{\circ} \mathrm{C}$ qualquer soro proveniente de queijo Minas, Prato, Parmesão ou Mussarela. Esse soro é mantido a temperatura ambiente até o próximo dia, quando é adicionado a outro soro fresco, é aquecido a $60^{\circ} \mathrm{C}$ e estocado novamente a temperatura ambiente. Esta operação é repetida por mais 2 ou 3 dias, até que a acidez atinja $85-90^{\circ} \mathrm{D}$ e apresente sabor e odor agradáveis. Furtado (1997) descreve obtenção similar, porém, mais simples, do soro fermento em laticínios brasileiros. Inicialmente é retirado soro fresco da fabricação do dia, sendo este inoculado com soro já fermentado de outra fabricação até que sua acidez atinja $100-130^{\circ} \mathrm{D}$. Quando se trabalha com leite crú, o cozimento da massa é geralmente mais elevado, cerca de $44^{\circ} \mathrm{C}$, e é nessa temperatura, que o soro é retirado no final da fabricação. O soro fermento resultante, é composto de uma microbiota variável, relacionada à região onde foi obtido, qualidade do leite e forma de propagação, tendo predominância de microrganismos termófilos. Ainda, de acordo com Furtado (1997), quanto mais alta a acidez no soro fermento, maior a predominância de L. helveticus.

Na Itália, o soro fermento é largamente utilizado na fabricação de queijos Parmigiano Reggiano, Grana Padano e outros queijos duros. No preparo inicial, o leite após a ordenha é filtrado e vertido em compartimentos pequenos para a subida do creme, onde permanecem por 6-12 horas. Após este processo "affioramento" parte do creme naturalmente separado é desnatado e junto com o 
MELO, R.T. et al. Lactobacillus helveticus e sua importância na indústria de laticínios. PUBVET, Londrina, V. 5, N. 9, Ed. 156, Art. 1057, 2011.

creme são carreadas bactérias não láticas, particularmente, as formadoras de esporos. O resultado é uma parcial seletividade na aglutinação dos microrganismos, que sobem com os glóbulos de gordura. Variações físicoquímicas durante este processo também afetam o flavor juntamente com 0 aumento da população de bactérias do ácido lático. Soro fermento natural é preparado para a fabricação prevista dos queijos do dia e, muito frequentemente, contém um misto de L. helveticus, L. delbrueckii subsp. bulgaricus e alguns lactococos (Neviani e Carini, 1994).

Diversos trabalhos têm comprovado que a microbiota no soro fermento é composta principalmente de lactobacilos termófilos, com predominância de $L$. helveticus e L. delbrueckii subsp. bulgaricus (Botazzi, 1977; Neviani e Carini, 1994, Furtado, 1997; Giraffa et al., 1998).

Durante o primeiro estágio do processo de fabricação dos queijos, lactobacilos termófilos provenientes do soro fermento prevalecem e representam um importante papel na acidificação da massa, durante o qual coliformes e clostrídios são inibidos (Neviani e Carini, 1994).

\section{Considerações finais}

Lactobacillus helveticus pode ser isolado em diferentes ecossistemas, como de soro fermento natural, de leites fermentados ou de queijos fabricados com leite não pasteurizado. Além disso, algumas cepas ainda são capazes de sintetizar compostos inibidores específicos (bacteriocinas), que dificultam o crescimento de alguns microrganismos patogênicos. Essa característica somada à capacidade de produzir grande quantidade de ácido lático, de predominar no soro fermento, de resistir a fagos e ao calor, de metabolizar galactose e outras características desejáveis aumenta os estudos sobre esse microrganismo de grande importância tecnológica para a indústria de laticíneos. 
MELO, R.T. et al. Lactobacillus helveticus e sua importância na indústria de laticínios. PUBVET, Londrina, V. 5, N. 9, Ed. 156, Art. 1057, 2011.

\section{Referências}

AMMAR EL TAHRA, M. A; EL SHAZLY, A; NASR, M. M.; EL SAADANY,M.; EL-TAHRA,M. A A Effect of using autolyzedstarter and cheese slurry on accelerationof Ras cheese ripening made from mixture of goat'sand cow's milk.Egyptian Journal ofDairy Science,Cairo, v. 22, n. 1, p. 6780,1994 .

AMRANE, A; PRIGEN, Y. Influence of media composition on lactic acid production rate from whey by Lactobaci/lus helveticus. Biotechnology Letters, Kew, v. 15, n. 3, p. 239-244, Mar. 1993.

ARNAUD, A; GIRAUD, 1. P. Bioquímica microbiana. In: SCRIBAN, R. Biotecnologia. São Paulo: Manole, 1985. capo2, p.47-102.

BOTAZZI, V. Cultura de fermentos táticos: cultura natural, staters, cultura combinada. In: CONGRESSO NACIONAL DE LATICÍNIOS, 4., 1977, Juiz de Fora. Anais... Juiz de Fora: EPAMIG, 1977.p.43-46.

CALLEGARI, M. L.; RIBOLI, R; SANDERS, 1. W.; COCCONCELLI, P. S.; KOK, 1.; VENEMA, G.; MORELLI, L. The S-layer gene of Lactobacillus he/veticus CNRZ 892: c1oning, sequence and heterologous expression. Microbiology Reading, v. 144, n. 3, p. 719-726,1998.

CARVALHO, A F. Systématique des bactéries propioniques laiteires: classification, nomenclature et identification. 1994. 227p. (Tese de Doutorado). ENSA, Rennes.

EZZAT N.; EL SODA M.; BOUILLANNE C.; BLANCHARD P. Cell wall associated proteinase in Lactobacillus he/veticus, Lactobacillus bu/garicus, Lactobacil/us /actis. Milchwissenschaft, Munchen, n. 40, n. 2, p. 140, Feb.1985.

FORTINA, M. G.; NICASTRO, G.; CARMINATI, D.; NEVIANI, E.; MANACHINI,P. L. Lactobacil/ushe/veticusheterogeneityin natural cheese starters: the diversity in phenotypic characteristics. Journal of Applied Microbiology, Oxford, v. 84, n. 1, p. 72-80, July 1998.

FOX, P. F.; LAW, J. Enzimology of cheese Ripening. Food Biotechnology, New York, v.5, n. 3, p. 239-262, Sept./Dec. 1991.

FURTADO, M. M. Manual prático da mussarela (pizza cheese). , São Paulo: Master Graf Editora, 1997. 70p.

FURTADO, M. M. Isolamento de bactérias láticas de leite cru e soro de queijo de leite cru da região do Serro, Minas Gerais. 1990b. 95p. Dissertação (Mestrado em Ciência e Tecnologia de Alimentos) - Universidade Federal de Viçosa, Viçosa.

GASSER, F. Eletrophoretic characterization of lactic dehydrogenases in the genus Lactobacil/us. Journal of General Microbiology, London, v. 62, p. 223-239, 1970.

GATTI, M.; FORNASARI, E.; NEVIANI, E. Cell-wall protein profiles of dairy thermophilic lactobacilli. Letters in Applied Microbiology, Oxford, v. 25, n. 5, p. 345-348, Nov. 1997.

GINZINGER, W.; SEBASTIANI, H. Proteolytic activity of thermophilic lactobacilli. DMZ, Lebensmittelindustrie und Milchwirtschaft, Munchen, v. 114,n.3,p.49-51,1993. 
MELO, R.T. et al. Lactobacillus helveticus e sua importância na indústria de laticínios. PUBVET, Londrina, V. 5, N. 9, Ed. 156, Art. 1057, 2011.

GIRAFFA, G., GATTI, M., ROSSETI, L. SENINI, L., NEVIANI, E. Molecular diversity within Lactobaci/lus he/veticus as revealed by genotypic characterization. Applied Environmental Microbiology, Washington, v. 66, n. 4, p. 1259-1265, Apr. 2000.

GIRAFFA, G.; ROSSETTI, L.; MUCCHETTI, G.; ADDEO, F.; NEVIANI, E. Influence of the temperature gradient on the growth of thermophilic lactobacilli used as natural starters in Grana cheese. Journal of Dairy Science, Champaign, v. 81, n. 1, p. 31-316, Apr. 1998.

GOMAA, M. S.; MEHANA, M. Y.; EL-RAZEK, M.B. Utilization of autolyzed starter to accelerate ripening process of Ras cheese. Egyptian Journal of Food Science, Cairo, v. 20, n. 3, p. 313-329, 1992

GUIMARÃES, P. Informações práticas sobre laticínios. 1991. Apostila. Não paginado.

HAMMES, W. P.; WEISS, N.; HOLZAPFEL, W.; BALOWS, A; TRUPER, H. G.; DWORKIN, M.; HARDER, W.; SCHLEIFER, K. H. The genera Lactobacillus and Carnobacterium. The prokaryotes: a handbook on the biology of bacteria: ecophysiology, isolation, identification, applications. 2.00 Germany, 1992. v. 2, p.1535-1594.

HÉBERT, E. M.; De GIORI, G. S.; RAYA, R. R. Isolation and characterization of a slowly milkcoagulating variant of Lactobaci/lus he/veticus deficient in purine biosynthesis. Applied Environmental Microbiology, Washington, v. 67, n. 4, p. 1846-1850, Apr. 2000.

HERTEL, C.; LUDWIG, W.; POT, R; KERSTERS,.K.; SCHLEIFER, K. H. Differentiation of lactobacilli occurring in fermented milk products by using oligonucleotide probes and electrophoretic protein profiles. Systematic and Applied Microbiology, Stuttgart, v. 16, n. 3, p. 463-467, 1993.

HICKEY, M. W.; HILLIER, A J.; JAGO, G. R. Transport and metabolism of lactose, glucose and galactose in homofermentative lactobacilli. Applied. Environmental Microbiology, Washington, v. 51, n. 4, p. 825-831, Apr. 1986.

IBRAHIM, E. M. Growth and biochemical behaviour of lactic acid bacteria in milk of buffaloes fed different ratios of live yeast cultures. Assiut Journal of Agricultural Sciences, Assiut, v. 22, n. 3, p. 165-177, 1991.

IBRAHIM, E. M.; MOHRAN, M. A; HANAFY,N. E. H. Growth and biochemical behaviour of some lactic acid starters in cow's and goat's milk. Assiut Journal of Agricultural Sciences,Assiut,v. 21, $n$. 2, p. 205-219,1990.

INGRAHAM,J. Effect of temperature, $\mathrm{pH}$, water activity, and pressure on growth. CeUular and Molecular Biology, Washington,v. n. p.1543-1554, 1987.

JOHNSON, M. E.; OLSON, N. F. Nonenzymatic browing ofMozzarella cheese. Journal of Dairy Science, Champaign, v. 68, n. 12, p. 3143-3147, Dec. 1985.

KANDLER, O.; WEISS, N. Regular non sporing Gran positive rods. In: SNEATH, P. H. A; MARR, N. S.; SHARPE, M. E.; HOLT, J. G. (eds). Bergey's manual of systematic bacteriology. Baltimore: Williams and Wikins, 1986. v. 2, p.1209.

KEMPER, M. A; DOYLE, R. 1. The cell wall of Bacillus subti/is is protonated during growth. In: Dans Bacterial growth and Lysis. New York: Plenum Press, 1993. p.245-252. 
MELO, R.T. et al. Lactobacillus helveticus e sua importância na indústria de laticínios. PUBVET, Londrina, V. 5, N. 9, Ed. 156, Art. 1057, 2011.

KYLA-NIKKILA, K.; HUJANEN, M.; LEISOLA, M.; PALVA, A Metabolic engineering of Lactobacillus helveticus CNRZ 32 for production of pure $L(+)$ lactic acid. Applied Environmental of Microbiology, Washington, v. 66, n. 9, p. 3841-3854, Sept. 2000.

LE BORGEOIS, P.; LAUTIER, M.; RITZENTHALER,P. Chromosome mappingin lacticacidbacteria.FEMS MicrobiologyReviews,Amsterdam, v. 12,p. 109-124,1993.

LORTAL, S.; VALENCE, F.; BIZET, C.; MAUBOIS, J.L. Eletrophoretic pattem of peptidoglycan hydrolases, a new tool for bacterial species identification. Research Microbiology, Paris, v. 148, n. 6, p. 461-474, July 1997.

LORTAL, S.; HEIJENOORT, 1. VAN; GRUBER, K.; SLEYTR, U. R; VANHEIJENOORT, 1. S-layer of Lactobacillus helveticus ATCC 12046: isolation, chemical characterization and reformation afier extraction with lithium chloride. Journal of General Microbiology, London, v. 138, n. 3, p. 611-618, Mar. 1992.

MAN, J. C. de; ROGOSA, M.; SHARPE, M. E. A medium for the cultivation of lactobacilli. Journal of Applied Bacteriology, Oxford, v. 23, n. 2, p. 130-135, 1960.

MATZDORF, R; CUPPETT, S. L.; KEELER, L.; HUTKINS, R W. Browning of Mozzarella cheese during high temperature pizza baking. Journal of Dairy Science, Champaign, v. 77, n. 10, p. 2850-2853, Oct. 1994.

MUKHERJEE, K. K.; HUTKINS, R. W. Isolation of galactose-fermenting thermophilic cultures and their use in the manufacture of low browning Mozzarella cheese. Journal of Dairy Science, Champaign, v. 77, n. 10, p. 2839-2849, Oct. 1994.

MURALIDHARAN, K.; WAKELAND, E. K. Concentration of primer and template qualitatively affects products in random amplifies polymorphic DNA PCR BioTechniques, Natick, v. 14, p. 362-364, 1993.

NEVIANI, E.; CARINI, S. Microbiology of Parmesan cheese. Microbiologie, Aliments, Nutrition, v. 12 , n. 1, p. 1-8, 1994.

NORTON, S.; LACROIX, C.; VUILLEMARD, 1. C. ROOuctionofyeast extract supplementation in lactic acid fermentation of whey permeate by immobilized cell technology. Journal of Dairy Science, Champaign, v. 77, n. 9, p. 2494-2508, 1994b.

NORTON, S.; LACROIX, C.; VUILLEMARD, J.c. Effect of $\mathrm{pH}$ on the morphology of Lactobacil/us helveticus in free-cell batch and immobilized-cell continuous fermentation. Food Biotechnology, New York, v. 7, n. 3, p. 235-251, 1993.

PILLOUD N.; MALLET, B. DNA probes for the detection of Lactobacillushe/veticus. Systematic Applied Microbiology, Jena, v. 13, n. 345, 1990.

REINHEIMER, J. A; MORELLI, L.; BOTTAZZI, V.; SUAREZ, V. Phenotypic variability among cells of Lactobacil/us he/veticus ATCC 15807. International Dairy Journal, Auntingdon, v. 5, n. 1, p. 97103, 1995. 
MELO, R.T. et al. Lactobacillus helveticus e sua importância na indústria de laticínios. PUBVET, Londrina, V. 5, N. 9, Ed. 156, Art. 1057, 2011.

SHINODA, T.; KUSUDA, D.; ISHIDA, Y.; IKEDA, N.; KANEKO, K.; MASUDA, O.; YANAMOTO, N. Survival of Lactobacillus helveticus strain CP53 in the human gastrointestinal tract. Letters Applied Microbiology, Oxford, v. 32, n. 2, p. 108-113, Feb. 2001.

SNEATH, P. H. A; KRIEG, N. R.; HOLT, 1. G.; SNEATH, P. H. A; STALEY, J. 1.; WILLIANS, S. T. Bergey's Manual of Determinatice Bacteriology. Baltimore: Willians \& Wilkins, 1994. 787p.

SNEATH,P. H. A; MAIR, N. S.; SHARP,M. E.; HOLT, 1. G. Bergey's Manual of Systematic Bacteriology. Baltimore:Willians\& Wilkins,1986.v. 2, 1599p.

STACKEDRANDT, E.; TEUBER, M. Molecular taxonomy and pylogenetic position of lactic acid bacteria. Biochimie, Paris, n. 70, p. 317-324, 1988.

TAILIEZ, P.; QUÉNÉE, P.; CCHOPIN, A Estimativa da diversidade entre as linhagens da coleção CNRZ: aplicação do RAPD a um grupo de lactobacilos. Lait, Paris, n. 76, p. 147-158, 1996.

THORMANN, C. E.; OSBORN, T. C. Use of RAPD \& RFPL markers for gemplasm evaluation. In: Applications of RAPD technology to plant breeding. Minneapólis, 1992. p. 9-11.

TORRIANI, S.; VESCOVO, M.; SCOLARI, G. An Overview on Lactobacil/us he/veticus. Annali di Microbiologia ed Enzimologia, Milano, v. 44, p. 163-191, 1994.

VALENCE, F.; DEUSTSCH, S. M.; RICHOUX, R; GAGNAIRE, V.; LORTAL, S. Autolysis and related proteolysis in Swiss cheese for two Lactobacil/us he/veticus straÍns. Journal of Dairy Research, Cambridge, v. 67, n. 2, p. 261-71, May 2000.

VESCOVO M., BOTAZZI, V. Characteristics of lactic acid bacteria in natural whey cultures. VI. Localization of proteolytic system of Lactobacil/us he/veticus. Scienza e Tecnica Lattiero Casearia, Parma, n. 30, p. 411, 1979.

WELSH, I.; MCCLELLAND, M. Fingerprinting genomes using PCR with arbitrary primers. Nucleic Acids Research, Oxford, n. 18, p. 7213-7218, 1990.

WILLIAMS, I. G. K; KUBELICK, A R.; LIVAK, K 1.; RAFALSKI, J. A; TINGEY, S. V. DNA polymorphisms amplified by arbitrary primers are useful as genetic markers. NucIeic Acids Research, Oxford, n. 18, p. 6531-6535, 1990.

WOLFF,K; SCHOEN,E. D.; RIJN, J. P. Optimizingthe gerationof randon amplified polymorfic DNAs in chrysantemum. Theoretical na Applied Genetics,Berlin, v. 86, p. 1033-1037,1993.

YAMAMOTO, N.; AKINO, A; TAKANO, T. Antihypertensive effect of the peptides derived from casein by an extracellular proteinase from Lactobacillus he1veticus CP790. Journal of Dairy Science, Champaign, v. 77, n. 4, p. 917-922, Apr. 1994. 